\title{
Effect of Laser Activated Sodium Hypochlorite on Sealing Ability of Two Endodontic Sealers Using Stereomicroscope-An In vitro Study
}

\section{Govula $\mathbf{K}^{*}$}

Narayana Dental College and Hospital, India

*Corresponding author: Kiranmayi Govula, Narayana dental college and hospital, Chintareddypalem Nellore, India, Tel: 09440932608; Email: govulakiranmayi24@gmail. com

\section{Research Article}

Volume 6 Issue 3

Received Date: July 01, 2021

Published Date: August 10, 2021

DOI: $10.23880 /$ oajds-16000302

\section{Abstract}

Introduction: The combination of various irrigants, irrigation techniques along with root canal sealers helps in achieving a three-dimensional seal in root canals, which is of clinical relevance. The present in-vitro study aims to assess and compare the efficacy of laser-activated $\mathrm{NaOCl}$ on the sealing ability of two endodontic sealers.

Materials and Methods: Forty extracted human single-rooted permanent teeth were collected and decoronated $12 \mathrm{~mm}$ from their apices. Instrumentation did with an $11 \mathrm{~mm}$ working length using Rotary Pro taper files to F3. All the teeth grouped into four $(n=10)$ based on irrigation protocol and sealer used as follows: Group A1 - Laser activated NaOCl + AH Plus Group A2 - Laser activated $\mathrm{NaOCl}$ + nano seal, Group B1 - NaOCl + AH Plus, Group B2 - $\mathrm{NaOCl}+$ nano seal. The lateral condensation technique did obturation. Roots stored in freshly prepared $1 \%$ methylene blue for 72 hours. The roots were split longitudinally along the long axis using a diamond disc underwater coolant, and markings made at 2, 4, and $6 \mathrm{~mm}$ from the apex. The depth of dye penetration and microleakage examined under a stereomicroscope (Magnus) at 30× magnification.

Results: Statistical analysis carried out by using the software, statistical package for social sciences [SPSS]. Results represented in the form of minimum, mean, and standard deviation.

Conclusion: The laser-activated $\mathrm{NaOCl}$ group exhibited better sealing ability than the control group. Among the two sealers, the Bio root RCS sealer showed less leakage \& better sealing ability than AH plus

Clinical Significance: Increasing the temperature of low concentration sodium hypochlorite solution by the action of the diode laser, not only enhances its immediate tissue dissolution capacity but also increased the dentin permeability by removing the smear layer. Further leading to better adhesion between the root canal sealer and the gutta-percha with the radicular dentin.

Keywords: Laser; Preheated sodium hypochlorite; Bioceramic sealer; Sealer penetrating ability; microleakage

\section{Introduction}

The rotary instruments solely are not enough in the cleaning of the root canal system because of the complex anatomy of the root apex. The lateral canals, accessory canals, along with the isthmi, become the host for microorganisms.
If they left untouched during the cleaning and shaping of root canals, there would be a possibility of reinfection.

The smear layer that is formed by the rotary instruments during the preparation of root canals can act as a barrier for root canal sealer penetration. It can result in poor intratubular 


\section{Open Access Journal of Dental Sciences}

tags formation leading to microleakage. It has proved that smear layer removal helps in disrupting the bacterial attachment, the discretion of their toxins and reduces the potentiality of bacteria. The presence of the smear layer impedes the penetration of both intracanal disinfectants and sealers into the dentinal tubules and can potentially compromise the three-dimensional seal. In this context, the root canal irrigation may help in increasing the efficacy of cleaning and shaping along with root canal instrumentation. Many studies results showed that in the laser in combination with irrigating solution groups, the bacterial reduction was more remarkable. Sodium hypochlorite is the most common endodontic irrigant, used in different concentrations. It has the bactericidal properties, ability to dissolve organic tissue, but it cannot remove the smear layer alone [1-6].

Gambargini, et al. and others found an increased amount of tissue dissolution of hypochlorite solution obtained by increasing the concentration, contact time, volume, and temperature of the solution. Another alternative approach to enhances its immediate tissue dissolution is by preheating the low concentration hypochlorite solution. Kamburis, et al. stated that the preheated hypochlorite solution removes organic debris and dissolves necrotic pulp tissue more efficiently when compared to unheated counterparts.

Heating sodium hypochlorite solutions can perform a chairside using any heating device that has the advantage of maintaining the desired irrigant temperatures within a short period from stock solutions stored at low temperatures [7].

The use of several activations systems /techniques showed improvements in the cleaning efficacy of irrigant solutions. Ekim and Erdemir evaluated the effect of different irrigations activate bye the laser in removing the smear layer; therefore, the laser can increase the success rate endodontic treatment [8]. The success of endodontic treatment not only depends upon this factor alone; it even depends upon sealer penetration depth. Sealers can be a reason for the root canal failure due to microleakage at sealer- dentin or sealer -core material interface. Adhesion of sealer to the root canal wall and monoblock formation can dominate this drawback. Among various methods in examining the penetrating ability of root canal sealers, the commonly used method is the linear measurement of dye penetration [9].

Hence the purpose of this in-vitro study was to examine and compare the effect of laser-activated $\mathrm{NaOCl}$ on the sealing ability of two endodontic sealers.

The null hypothesis was,

- The sealing ability of the two sealers has no difference after irrigation with laser-activated $\mathrm{NaOCl}$ in comparison with irrigation with normal $\mathrm{NaOCl}$.

- The sealing ability of bioceramic sealer has no difference when compared with AH Plus.

\section{Materials and Methodology}

The in-vitro study carried out in the Conservative Dentistry \& Endodontics and Periodontics departments at our institution. This in-vitro study obtained ethical clearance from the institutional ethical committee with IECNDCH/2019/P-10.

Forty extracted human single-rooted permanent teeth free of fractures cracks, selected for this study. Teeth were decoronated $12 \mathrm{~mm}$ from the apex followed by access preparation of the canals followed by the instrumentation done with $11 \mathrm{~mm}$ working length, canal preparation done by using crown down technique up to F3.

The teeth were randomly divided [ $\mathrm{n}=20]$ into two groups based on irrigating solution protocols.

Group A- Laser activated sodium hypochlorite

Group B-Sodium hypochlorite without preheating

After irrigation groups subdivided into subgroups $n=10$ based on root canal sealer used

Group A1 =Laser activated $\mathrm{NaOCl}+$ Bioroot RCS

Group A2 = Laser activated $\mathrm{NaOCl}+\mathrm{AH}$ plus sealer

Group B1 $=\mathrm{NaOCl}+$ Bioroot RCS

Group B2 $=\mathrm{NaOCl}+\mathrm{AHplus} \mathrm{sealer}$

For laser application, 980 nanometres diode laser, introduced into the canal until the apical region. According to the manufacturer's instructions, after placing it into the canal, the laser was activated and withdrawn from the root canal with a helicoidal movement for a total irradiation cycle of 20 sec (Table 1).

\begin{tabular}{|c|c|}
\hline Type of Laser & Diode \\
\hline Emission Mode & Continuous \\
\hline Time On \& Off & 20 Sec \\
\hline Delivery System & Laser Diode to fiber-coupled system \\
\hline $\begin{array}{c}\text { Energy } \\
\text { Distribution }\end{array}$ & In Focus mode \\
\hline Peak Power & 1.5 Watts \\
\hline Average Power & 0.7 Watts \\
\hline Frequency & $15 \mathrm{HZ}$ \\
\hline Duty Cycle & $50 \%$ \\
\hline
\end{tabular}

Table 1: Laser Parameters.

Obturation was done be lateral condensation technique, and the samples were stored in a humid atmosphere at 370c for 24 hours. Later the surfaces of samples were dried, and two coats of colored nail varnish applied on the surface 2 
mm short of the apex. Roots stored in freshly prepared $1 \%$ methylene blue for 72 hours. Following this, the samples rinsed for 15 minutes under tap water, and roots were split longitudinally along the long axis of the tooth. The depth of the dye penetration examined under stereomicroscope under 30x magnification.

The microleakage at the sealer-dentin interface of the two root canal sealers evaluated, and values obtained in units. The values converted into millimeters for vertical dye penetration and micrometer horizontal dye penetration using the following formula,

Number of units

Eyepiece Magnification $\times$ zoom magnification $=$ value in millimeters

Number of unit $\times 1000$

Eye piece Magnification $\times$ zoom magnification $=$ value in micrometers

\section{Results}

Statistical analysis carried out by using the SPSS software. The available data represented in the form of minimum, mean, and standard deviation as descriptive statistics. Independent sample t-test used to determine the significant difference between the two groups for horizontal and vertical dye penetration, taking the level of significance as $\mathrm{p} \leq 0.05$ for all tests mentioned in Tables 2-4.

\begin{tabular}{|c|c|c|c|c|c|}
\hline Side & Frequency & Mean \pm SD & Mean Difference & t Value & p Value \\
\hline \multicolumn{6}{|c|}{ Vertical } \\
\hline Group A1 & 20 & $4.63 \pm 0.35$ & \multirow{2}{*}{0.71} & \multirow{2}{*}{4.97} & \multirow{2}{*}{$<0.001^{*}$} \\
\hline Group B1 & 20 & $5.34 \pm 0.53$ & & & \\
\hline \multicolumn{6}{|c|}{ Vertical } \\
\hline Group A2 & 20 & $5.61 \pm 0.27$ & \multirow{2}{*}{2.96} & \multirow{2}{*}{15.321} & \multirow{2}{*}{$<0.001^{*}$} \\
\hline Group B2 & 20 & $8.57 \pm 0.81$ & & & \\
\hline
\end{tabular}

Table 2: Independent Sample ' $t$ ' Test: ${ }^{*} \mathrm{P}<0.05$ (significant), ${ }^{* *} \mathrm{p}>0.05$ (Not significant).

\begin{tabular}{|c|c|c|c|c|c|}
\hline Side & Frequency & Mean \pm SD & Mean Difference & T Value & p Value \\
\hline \multicolumn{5}{|c|}{ Horizontal } \\
\hline Group A1 & 10 & $27.65 \pm 1.73$ & \multirow{2}{*}{0.567} & \multirow{2}{*}{10.144} & $<0.001^{*}$ \\
\hline Group B1 & 10 & $33.32 \pm 0.31$ & Horizontal & \multirow{2}{*}{3.368} & $<0.003^{*}$ \\
\hline Group A2 & 10 & $33.97 \pm 0.54$ & \multirow{2}{*}{1.18} & & $<$ \\
\hline Group B2 & 10 & $35.15 \pm 0.96$ &
\end{tabular}

Table 3: Independent Sample ' $\mathrm{t}$ ' Test: ${ }^{*} \mathrm{P}<0.05$ (significant), ${ }^{* *} \mathrm{p}>0.05$ (Not significant).

\begin{tabular}{|c|c|c|c|c|c|}
\hline Side & Frequency & Mean \pm SD & Mean Difference & T Value & p Value \\
\hline \multicolumn{6}{|c|}{ Horizontal } \\
\hline Group Al & 10 & $20.01 \pm 2.00$ & \multirow{2}{*}{6.670} & \multirow{2}{*}{9.874} & \multirow{2}{*}{$<0.001 *$} \\
\hline Group Bl & 10 & $26.68 \pm 0.73$ & & & \\
\hline \multicolumn{6}{|c|}{ Horizontal } \\
\hline GroupA2 & IO & $27.77 \pm 0.95$ & \multirow{2}{*}{1.010} & \multirow{2}{*}{2.672} & \multirow{2}{*}{$<0.016^{*}$} \\
\hline GroupB2 & 10 & $28.78 \pm 0.71$ & & & \\
\hline
\end{tabular}

Table 4: Independent Sample ' $t$ ' Test: ${ }^{*} \mathrm{P}<0.05$ (significant), ${ }^{* *} \mathrm{p}>0.05$ (Not significant).

For vertical dye penetration, there was a difference found between groups A1 \& B1 and groups A2 \& B2. For horizontal dye penetration, there was a significant $[p<0.05]$ difference at $2 \mathrm{~mm}$ and $4 \mathrm{~mm}$ between the groups $\mathrm{A} 1 \& \mathrm{~B} 1$ and $\mathrm{A} 2$ \& B2, represented in the three graphs, $1 \& 3$. 

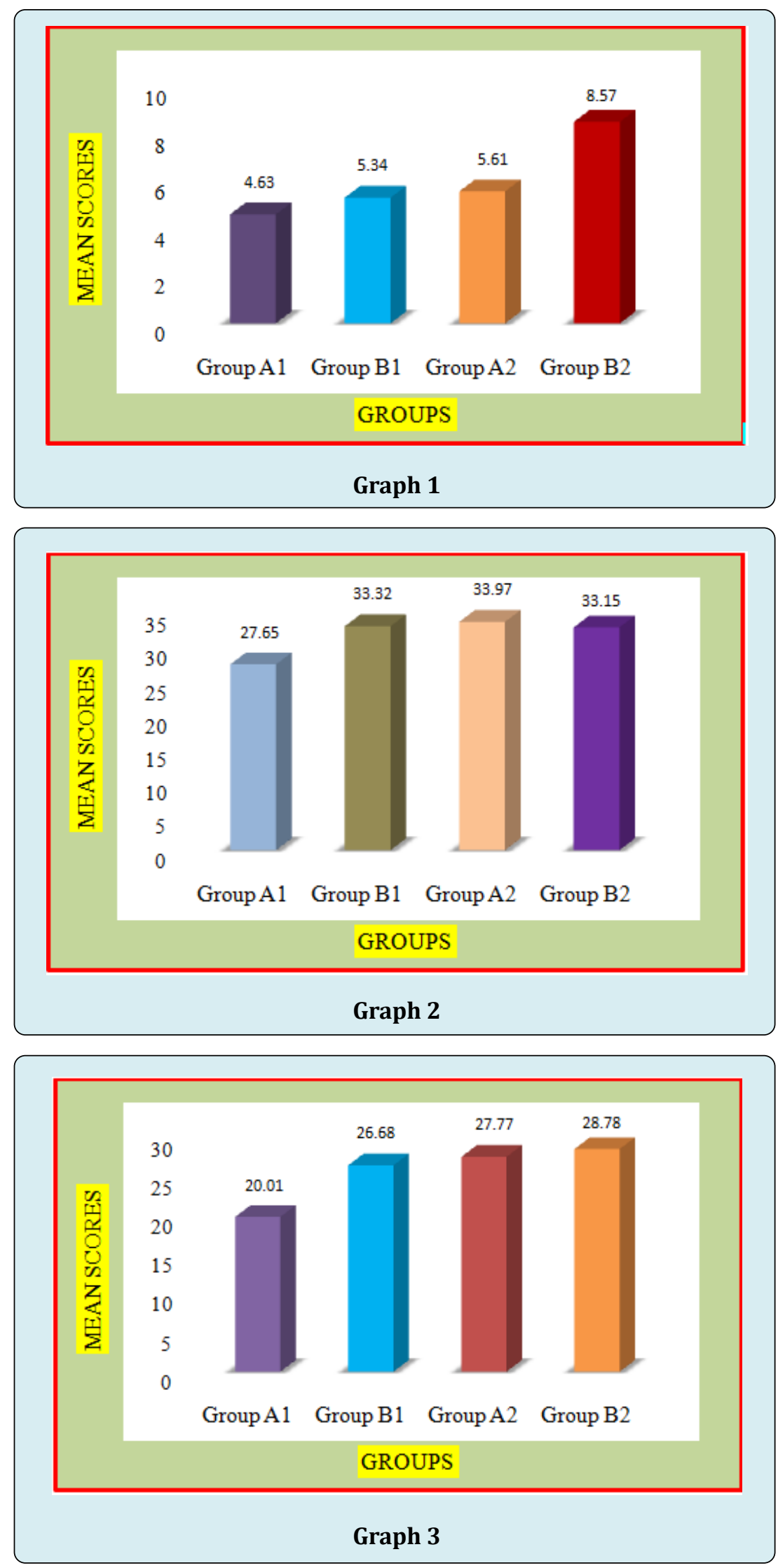


\section{Open Access Journal of Dental Sciences}

\section{Discussion}

The phenomenon of capillarity is the principle behind the method of dye penetration. In this method, the assessment of apical leakage done by submerging the tooth apex in the dye where the dye penetrates by negative or positive pressure through the spaces present in the interface of sealer and root canal walls [10]. The teeth have to be sectioned longitudinally, transversely or cleared, for recording the linear penetration of the dye. Many studies have studied the sealing ability of the sealers using methylene blue as a dye [11]. Methylene blue is inexpensive, easy to manipulate and has a high degree of staining the lower molecular weight bacterial toxins [12].

The critical factor in the success of root canal treatment is an efficient and thorough cleaning and shaping of root canals, which is possible only by eliminating the microorganisms. Another critical factor in success is three-dimensional obturation. It is without any apical leakage because it allows the microorganisms to invade the root canal, impeding the prognosis of periapical healing [13].

The antibacterial effect of intracanal medicament enhanced by the removal of the smear layer as well as adequately cleaned root canal system. Moreover, the removal of the smear layer helps to improve the seal between the obturating material and the canal wall.

Recently laser therapy in dental applications is growing day by day, especially in the field of endodontics. Out of all the applications, the efficient use of laser is successful in the removal of the smear layer that remains on the instrumented canal wall.

Since apical leakage, considered as the main factor in the failure of conventional root canal preparation, the application of diode laser may be beneficial as it efficiently disinfects the root canal walls, removes the smear layer, and improves the seal.

Several studies have supported that the use of diode laser as an adjuvant to conventional root canal disinfection can have an added value $[14,15]$. The use of diode laser remains attractive in root canal preparation as it well designed with small dimensions, low-cost power output, and operating modes [16] to achieve disinfection and sterilization by entering into the root canals [17]. Many studies stated that the root canal preparation combines with $980 \mathrm{~nm}$ diode laser was able to clean canal walls with open dentinal tubules. The result was a significant reduction in apical leakage.

As the penetration depth of the diode laser is lower than that of ND -YAG laser, the risk of thermal side effects was minimal [18]. As diode laser can heat sodium hypochlorite solution, their combination can lead to extensive disinfection by reducing the bacterial load. Their combination shows a synergistic effect with intensified bactericidal action [19]. The combined disinfection procedure may result up in a 98\% bacterial reduction. A recent study by Preethee T, et al. demonstrated superior bacterial efficacy of $980 \mathrm{~nm}$ diode laser combined with irrigants than canals disinfected with irrigants alone [20].

In our study, the flow of methylene blue dye in the tooth through the apex determined the sealer penetration. Methylene blue dye has the potential to enter the obturated canals through the lateral canals and accessory canals in the root apex or space between the dentin-sealer-core material interfaces.

The study results proved that the laser-activated groups have less dye penetration. The vertical and horizontal dye penetration scores showed a significant difference in the laser-activated group. The leakage in the apical and coronal region is significantly less in the laser-activated groups than the other group. Reduction in the leakage may be attributed to the action of diode laser in root canals by removing the smear layer, thereby increasing the dentin permeability. This finding is in correlation with the previous study by Marchesan, et al. [16] in which root canal walls irradiated under the same conditions and were analyzed with scanning electron microscopy and showed evaporation of smear layer and visible but not opened, dentinal tubules $[16,20]$.

Among the two sealers, BC sealer showed less leakage giving inference of good sealing ability. Despite better penetration of $\mathrm{AH}$ plus into micro irregularities, the inadequate bonding between the sealer and the guttapercha could have allowed the fluid leakage at the interface, resulting in a small amount of vertical dye penetration. Bioceramic sealer [BC sealer] is hydrophilic and can expand up to $0.2 \%$ after its setting reaction. It has enhanced chemical $\&$ micromechanical bonding resulting in an excellent seal.

The bonding of the sealer could be the probable reason for lesser microleakage in this sealer group. Among the methods to increase the temperature of sodium hypochlorite preheating in syringes has the disadvantage of heat dissipation. The laser activation with $980 \mathrm{~nm}$ increases with the temperature below 550c, which can be tolerated by the surrounding tissues by making it a better method to increase the efficacy of sodium hypochlorite.

\section{Conclusion}

Within the range of limitations of this in vitro study it is concluded, that

- The laser-activated $\mathrm{NaOCl}$ group exhibited better sealing 
ability than the control group.

- Among the two sealers, the Bio root RCS sealer showed less leakage \& better sealing ability than $\mathrm{AH}$ plus.

Ethical Considerations: Ethical approval for this study given by the Institutional Ethics Committee of Narayana Dental College \& Hospital [IECNDCH/2019/P-10].

\section{References}

1. Shahriari S, Kasraei S, Roshanaei G, Karkeabadi H, Davanloo H (2017) Efficacy of sodium hypochlorite activated with laser in intracanal smear layer removal: a sem study. J Lasers Med Sci 8(1): 36-41.

2. Sirtes G, Waltimo T, Schaetzle M, Zehnder M (2005) The effects of temperature on sodium hypochlorite short-term stability, pulp dissolution capacity, and antimicrobial efficacy. J Endod 31(9): 669-671.

3. Moon YM, Kim HC, Bae KS, Baek SH, Shon WJ, et al. (2012) Effect of laser-activated irrigation of 1320-nanometer $\mathrm{Nd}$ : YAG laser on sealer penetration in curved root canals. J Endod 38(4): 531-535.

4. Arslan H, Ayranci LB, Karatas E, Topçuoğlu HS, Yavuz MS, et al. (2013) Effect of agitation of EDTA with 808-nanometer diode laser on the removal of smear layer. J Endod 39(12): 1589-1592.

5. Mancini M, Cerroni L, Iorio L, Armellin E, Conte G, et al. (2013) Smear layer removal and canal cleanliness using different irrigation systems (EndoActivator, EndoVac, and passive ultrasonic irrigation): field emission scanning electron microscopic evaluation in an in vitro study. J Endod 39(11): 1456-1460.

6. Asnaashari M, Safavi N (2013) Disinfection of contaminated canals by different laser wavelengths, while performing root canal therapy. J Lasers Med Sci 4(1): 8-16.

7. Veríssimo DM, do Vale MS (2006) Methodologies for assessment of apical and coronal leakage of endodontic filling materials: a critical review. J Oral Sci 48(3): 93-98.

8. Camps J, Pashley D (2003) Reliability of the dye penetration studies. J Endod 29(9): 592-594.

9. Lucena Martín C, Ferrer Luque CM, González Rodríguez MP, Robles Gijón V, Navajas Rodríguez de Mondelo JM (2002) A comparative study of apical leakage of Endomethasone, Top Seal, and Roeko Seal sealer cement. J Endod 28(6): 423-426.

10. Zmener O, Pameijer CH, Macri E (2005) Evaluation of apical seal in root canals prepared with a new rotary system and obturated with a methacrylate-based endodontic sealer: an in vitro study. J Endod 31(5): 392395.

11. Brandão CG, de Moraes IG, Bramante CM (2001) Apical sealing ability of ionomeric endodontic sealers. Rev FOB 9: 29-34.

12. Castelo Baz P, Martin Biedma B, Ruiz Pinon M, Rivas Mundina B, Bahillo J, et al. (2012) Combined Sodium Hypochlorite and $940 \mathrm{~nm}$ Diode Laser Treatment Against Mature E. Faecalis Biofilms in vitro. J Lasers Med Sci 3(3): 116-121.

13. Hmud R, Kahler WA, George R, Walsh LJ (2010) Cavitational effects in aqueous endodontic irrigants generated by near-infrared lasers. J Endod 36(2): 275278.

14. De Souza EB, Cai S, Simionato MR, Lage Marques JL (2008) High-power diode laser in the disinfection in the depth of the root canal dentin. Oral Surg Oral Med Oral Pathol Oral Radiol Endod 106(1): 68-72.

15. Kreisler M, Kohnen W, Beck M, Haj HA, Christoffers AB, et al. (2003) Efficacy of $\mathrm{NaOCl} / \mathrm{H}_{2} \mathrm{O}_{2}$ irrigation and GaAlAs laser in decontamination of root canals in vitro. Lasers Surg Med 32(3): 189-196.

16. Marchesan MA, Brugnera A, Ozorio JE, Pecora JD, Sousa Neto MD (2008) Effect of 980-nanometer diode laser on root canal permeability after dentin treatment with different chemical solutions. J Endod 34(6): 721-724.

17. Lee Mt, Bird PS, Walsh LJ (2004) Photo-activated disinfection of the root canals: a new role of the lasers in endodontics. Aust Endod J 30(3): 93-98.

18. Wang X, Sun Y, Kimura Y, Kinoshita J, Ishizaki NT, et al. (2005) Effects of Diode Laser Irradiation on Smear Layer Removal from Root Canal Walls and Apical Leakage after Obturation. Photomed Laser Surg 23(6): 575-581.

19. Gutknecht N, Franzen R, Schippers M, Lampert F (2004) Bactericidal effect of a 980-nm diode laser in the root canal wall dentin of bovine teeth. J Clin Laser Med Surg 22(1): 9-13.

20. Preethee T, Kandaswamy D, Arathi G, Hannah R (2012) Bactericidal effect of the $908 \mathrm{~nm}$ diode laser on Enterococcus faecalis in infected root canals. J Conserv Dent 15(1): 46-50. 